\title{
Improve the Voltage Profile by using DGS and Dstatcom Optimum Placement and Sizing with Help of Back Tracking Search Algorithm
}

\author{
M.Suneetha, R.Srinivasa Rao, B.Subramanyam
}

\begin{abstract}
In Modern Trends in power system, the Distributed Generators (DGs) and FACT Devices are used in Distributed System are becoming more important due to the increase the electrical energy demand. The sizing off DGs and DSTATCOM sizing and proper location has important in power systems which obtaining their better voltage profiles. In this paper, decide the ideal area and estimating DGs and DSTATCOM to power losses decreases and recover the Voltage Profile by the new swarm advancement method explicitly Back Tracking Search Algorithm $(B S A)$ is considered for various burden models.
\end{abstract}

Keywords: Distributed Generation, DSTATCOM, Back Tracking Search Algorithm, different load models.

\section{INTRODUCTION}

The Distribution framework intends to give the electrical vitality to clients with larger amounts of interest. Consistent development of burdens expands the power misfortunes with increment the current and diminishes the voltage level in the dissemination arrange.To solve these difficulties by using DGs and DSTATCOM to enhance the operation of power syustem on Distribution side. Celli.G, Giani.G, Loddo.M[1]presents the operating point and optimizing for all distributed generators by using genetic algorithm to improve the voltage profile on power system of distribution network. The intend of distribution system is to supply the customers with higher levels of demand. The Current leading to the increase of power losses with continuous growth of loads increases and decreases the voltage profile in the distribution network. These difficulties are solve by using DGs and to enhance the distribution network operation. U.Eminoglu, M.H. Hocaoglu [2]proposed backward voltage and forward voltage bring up to date by using Voltage equation of polynomial and back ward stepladder equation for each branch of different loading circumstances, different voltage stages of $\mathrm{R} / \mathrm{X}$ Ratios. .Zhu.D, Broadwater.R.P; Kwa-sur Tam; Segum.R[3] presents The Optimum location of DGs are required for different time varying loads and to Qian, Allan.M, Yuan.Y [4] planned study the investigation of placement of DG to control load models effect on the evaluation of energy losses and at various voltage levels

Revised Version Manuscript Received on August 19, 2019.

M. Suneetha, Department of Electrical and Electronics Engineering , Narayana- Engineering College, Muthukur Road, NH-5 A.K.Nagar, Nellore, AP, India.

R. Srinivasa Rao, Department of Electrical Engg, Jawaharlal Nehru Technological University College of Engineering, Pita-puram Road, Kakinada, AP, India.

B. Subramanyam, S.V. University College of Engg, Sri Padmavati Mahila Visvavidyalayam, Tirupthi, Andhra Pradesh, India. improve the reliability and efficiency .Chengke Zhou, Kejun

using 38-node network in power system.MansourcehZangiabadi, Renefeuiller, Hamid Lesani[5] presents dependent on the vitality request designating the advantages of Distributed generators to improve the financial presentation and watch cost affectability investigation of conveyed organize.Duong Quoc Hung ,NadarajahMithulanathan[6] presents the ideal size of 4 distinctive Distributed Generations types by utilizing an improved expository (IA) strategy to get the ideal area for Four diverse Dg types.MasoudEsmaili[7] presents optimal placement of DGs by using Fuzzification to improve the voltage stability and also conceive the more than one DGs with exchanging the non linear programming into mixed integer NLP.Kazemi.A, Kalantari.M, \& Zakerinia.A.M[8] presents improve the reliability, minimization the cost and maximizing DG capacityby using Genetic Algorithm and dealing with DG assignment and sizing. Member.S, .Abu-mouti F.S [9] concentrate on optimize DG size, improve the power factor and network constraints by using ABC optimization Technique. In any case, in down to earth frameworks the heap does not consistent and it shifts contrastingly for different client types. "-In appropriation side, comprises of various burdens i.e business, consistent, Industrial and blended burdens and so on., Due to these heaps are impact on the dynamic and responsive power, Voltage and recurrence of the framework"Naruttam Kumar Roy[10] showed results of voltage dynamics in faulted system of distribution side by using DSTATCOM. Zahersaafin, Fouad Zaro[11] presents a new strategy for DSTATCOM of tuning controller gains based on artificial neural networks and hybrid article swarm optimization and pick up the profile of voltage of the network of distribution side. .Haque.M [12] presents effect of voltage in need when variable loads has a main effect on planning studies of distribution system. Singh et al[13] Studied Voltage problems and power losses maintain on the distribution side with the dissimilar models of load effects by placing the Distribution Generators sizing .

\section{DSTATCOM}

DSTATCOM i.e Distributed Static Compensator is made up of voltage -source inverter with static compensator. It is utilized for the compensative responsive power and diminishes the voltage droops. It can give the right measure of slacking or driving receptive current remuneration with variety of burdens."-The major components of DSTATCOM

Published By

Blue Eyes Intelligence Engineering 
are one or more inverter modules", dc capacitor and an ac filter, a PWM control strategy, a transformer to match the inverter output to the line voltage."-In DSTATCOM, a voltage source inverter translates a dc voltage into three phase ac voltage that is synchronized with ac line through capacitor and reactor (ac filter) IGBT or GTO voltage source converter function is to controlled in magnitude and phase angleof Voltage and to compensate whichever lagging or leading imajinary component of current confide nased on requirement of reactive compensation". The DSTATCOM has L-C filter which harmonics reduce on distribution network

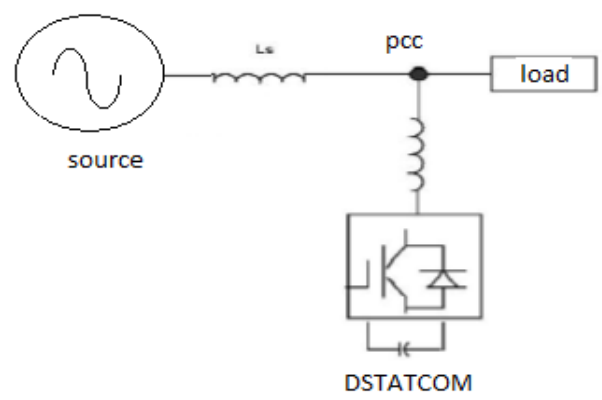

Fig.1 DSTATCOM

\section{PROBLEM FORMUILATION}

The Problem Formulation is to control the Voltage sag and power losses which varies with load.

\section{(i). Objective Function}

"The main intention of objective function is to diminishing the total power losses going on while contribute the individual loads".

$$
\text { Minimum function }=\mathrm{P}_{\text {loss }}=\sum_{i=1}^{n l} I^{2} R \ldots
$$

\section{(ii). System Constraints}

The voltage maintain with in limits on system

$$
\mathrm{V}_{\min }<\mathrm{V}<\mathrm{V}_{\max }
$$

Vmax and Vmin are maximum and minimum permissible voltage of given bus.

The power constraints are

$$
\left|P_{\text {minij }}\right| \leq \mid \text { Plineij }|\leq| \text { Pmaxij } \mid
$$

Pmaxij and Pminij are maximum and minimum allowable power flow through out the line and Plineij is the total line powerof $\mathrm{i}$ bus line to $\mathrm{j}$ bus line.

(iii). Load Flow:

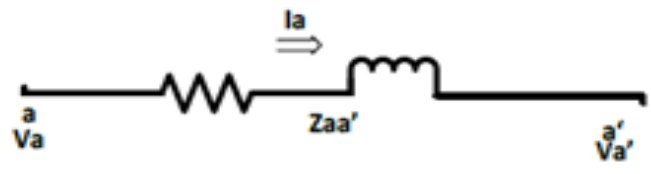

Fig.2 Typical Single phase feeder

$$
\mathbf{V}_{\mathrm{a}}=\mathbf{V}_{\mathrm{a}}{ }^{\prime}-\mathbf{I}_{\mathrm{a}} \mathbf{Z}_{\mathrm{aa}}{ }^{\prime}
$$

Figure 1 shows the typical section of a single phase feeder. The fb sweep considers the complex load at each bus to be constant. NR method for load flow studies is superior than Gauss Seidel techniques in the assessment of delivery frame works, because of the exclusive highlights of distribution network. These highlights make the circulation of power system frameworks and calaculations extraordinary and fairly hard to examine when contrasted with the transmission frameworks. Different techniques are accessible to complete the examination of adjusted and uneven outspread conveyance frameworks and can be separated into tw3o classes. The main sort of techniques is used by legitimate change of existing strategies, for example NR and GS strategies. Then again, the second gathering of techniques depends on in reverse and forward compass procedures utilizing Kirchhoff's laws.

$$
I_{i}=\left(P_{i}-j Q_{i}\right) / V_{i}
$$

\section{(iv). Types of DG sources}

They are four types of DG sources based on capability of sending active and reactive power.

Type 1: This type of DG s produce Active power like fuel cells and PV arrays which are linked to the grid

el cells, which are connected to the grid by means of inverters.

Type 2: This type of DGs produce Reactive power (Q) like Synchronous condensers.

Type 3: This type of DGs maintain both reactive power consumers and Active power producers (PQ) which produce requirement of absorbs reactive power and produces Active power from the grid.

Type 4: These types of DG produces reactive power based on control voltage drop and requirement of reactive power to which they are connected. The True and Reactive power manufacturers maintain the PV bus voltage regulator.Diesel generators are and converters with Wind turbines categorized as Type 4 DGs.

Formulated the inject reactive and active powers of the ith node are as follows :

$$
\begin{aligned}
& \mathrm{Q}_{\mathrm{i}}=\mathrm{Q}_{\mathrm{DG}}-\mathrm{Q}_{\mathrm{Di}}=\alpha_{\mathrm{i}} * \mathrm{P}_{\mathrm{DGi}}-\mathrm{Q}_{\mathrm{Di}} \\
& \mathrm{P}_{\mathrm{i}}=\text { Active power at it } \mathrm{h} \text { bus }=\mathrm{P}_{\mathrm{DGi}}-\mathrm{P}_{\mathrm{Di}}-(4) \\
& \alpha_{\mathrm{i}}=\tan \left(\mathrm{co}^{-1}\left(\text { Power Factor angle of } \mathrm{DG}_{\mathrm{i}}\right)\right) *(\mathrm{sign}) \\
& \text { where } \mathrm{P}_{\mathrm{DGi}} \text { and } \mathrm{Q}_{\mathrm{DG}} \text { are active and Reactive power of } \mathrm{DGs} \\
& \text { which connected to } \mathrm{i}^{\text {th }} \text { node. } \\
& \mathrm{P}_{\mathrm{Di}} \text { and } \mathrm{Q}_{\mathrm{Di}} \text { are the Active power and Reactive power of ith } \\
& \text { node. }
\end{aligned}
$$

\section{VOLTAGE DEPENDENT LOAD MODEL}

In load flow studies, first assume that reactive and active power loads are constant, apart from the magnitude of voltages in ith bus. But in practically loads are considered based on line voltage are dependent and their relationship. Different type of loads are used. They are industrial , residential and commercial loads. In Voltage Dependent load model, the virtual between load and voltage is articulated as

$$
\begin{aligned}
& \mathrm{Q}_{\mathrm{L}}=\mathrm{Q}_{\mathrm{L} 0} * \mathrm{~V}^{\mathrm{nq}} \\
& \mathrm{P}_{\mathrm{L}}=\mathrm{P}_{\mathrm{L} 0} * \mathrm{~V}^{\mathrm{np}}
\end{aligned}
$$

Where nq and $\mathrm{np}$ are reactive power and active power exponents.QL0 and PL0 are tje reactive and real power at nomeal voltages and QL and PL are reactive and real powers. $\mathrm{V}$ is node voltage magnitude at node i respectively. 
$\gamma, \beta, \alpha$ are the percentage of industrial, residential and commercial load at each node.

The equations for the voltage dependent load model can expressed as :

$$
\begin{aligned}
& \mathrm{P}_{\mathrm{L}}=\alpha \mathrm{P}_{\mathrm{L}_{0}} \mathrm{~V}^{\mathrm{npr}}+\beta \mathrm{P}_{\mathrm{L}_{0}} \mathrm{~V}^{\mathrm{npc}}+\gamma \mathrm{P}_{\mathrm{L}_{0}} \mathrm{~V}^{\text {npi }} \\
& \mathrm{Q}_{\mathrm{L}}=\alpha \mathrm{Q}_{\mathrm{L}_{0}} \mathrm{~V}^{\mathrm{npr}}+\beta \mathrm{Q}_{\mathrm{L}_{0}} \mathrm{~V}^{\mathrm{npc}}+\gamma \mathrm{Q}_{\mathrm{L}_{0}} \mathrm{~V}^{\mathrm{npi}} \\
& \text { and } \alpha+\beta+\gamma=1
\end{aligned}
$$

The estimations of the exponents of reactive and true power values are utilized in present work for modern, private and business burdens are given in Table -1 .

Table - 1: Load types and exponent values

\begin{tabular}{|c|c|c|}
\hline Load Type & $\mathbf{n p}$ & $\mathbf{n q}$ \\
\hline Industrial & $\mathbf{0 . 1 8}$ & $\mathbf{6}$ \\
\hline Constant & 0 & 0 \\
\hline Residential & 0.91 & 4.03 \\
\hline Mixed & - & - \\
\hline Commercial & 1.50 & 3.03 \\
\hline
\end{tabular}

"As indicated by Table 1, the voltage example (nq) of the receptive burden is very high in the vast majority of the heap types when contrasted with the genuine power type (np), especially for modern burdens, hence thought of voltage reliance of responsive burdens is important for DG arranging ponders".

\section{BACKTRACKING SEARCH ALGORITHM (BSA)}

The Back Tracking Algorithms (BSA)are swarm optimization technique and used to satisfy the system constraints in the system and solve the optimal placement the devices which meet the system constraints with in limits. The BSA is a population based iterative EA designed to be elucidated by following five processes: (I).Initialization, (II). Selection-I (III) Mutation, (IV) Crossover and (V) Selection-II. The structure of BSA is quite simple and easily adapted to different numerical engineering optimization problems.

The BSA five main procedures are outlined below:

\section{(i) Initialization}

First Initiation the population and it denoted as $\mathrm{Pij}$ population in below Eq

$$
\mathrm{P}_{\mathrm{ij}}=\mathrm{LB}_{\mathrm{j}}+(\mathrm{UB} \mathrm{j}) \text { rand }(\ldots .) \quad \mathrm{i} \forall \mathrm{N} \& \mathrm{j} \forall \mathrm{D}
$$

\section{(ii) Determine the historical population oldP:}

In step, decide the historical population oldP which is used for scheming the search direction".

The initial historical population is indomitable as

$$
\operatorname{OldP}_{\mathrm{ij}}=\mathrm{LB}_{\mathrm{j}}+\operatorname{rand}(\ldots) \text {. (UB } \mathrm{UB}_{\mathrm{j}} \quad \mathrm{i} \forall \mathrm{N} \quad \& j \forall \mathrm{D}
$$

"-After got oldP, then permuting function is applied to system and observe randomly change the order of oldP individuals in old function and randomly permuting function can formulated as

OldP:= Permuting function of oldP

\section{(iii)Process of Mutation}

"In this step generates the initial form of the population mutant trial. Here calculation of the matrix search direction by using historical population; the BSOA generates a trial population, taking partial advantage of its experiences from previous generations.

Mutant $=$ F. $($ oldP-P $)+\mathrm{P}$

Fis the controls - amplitude of the search direction- matrix.

\section{(iv) determine the preliminary populace $T$ :}

Game plan of the preliminary populace $\mathrm{T}$, first estimate the preliminary - populace is Mutant. Preliminary people with improved population by using advanced objective population (better than old) for advancement issue.

\section{(v) Selection - II}

In assurance II orchestrate, the fundamental peoples $\mathrm{T}$ is the favored wellbeing regards over the contrasting $\mathrm{P}$ is are used with invigorate the Pis subject to a ravenous decision. If the best indivi-dual of $\mathrm{P}$ (Pbest) has an unrivaled health regard than the overall least worth procured, the overall minimizer is invigorated to be Pbest and the overall least worth is revived to be the wellbeing estimation of Pbest

\section{METHODOLOGY}

"-BSA utilizes two arrangements of populace, one preliminary populace and other recorded populace which goes about as swarm memory". Along these lines the posterity contains the attributes of both present and recorded populace which is useful in acquiring snappy and solid outcomes. The plausible areas for the DG can be anyplace between first transport to the all out number of transports while the DG size is considered to lie somewhere in the range of $0 \mathrm{MW}$ and $2 \mathrm{MW}$.

At first target work (net power shortfall) for the preliminary populace is determined utilizing clear strategy. At that point utilizing change, hybrid and choice procedures off springs are created. The power misfortune is determined for the offsprings, the posterity with lower wellness worth supplant the individuals from beginning populace accordingly making another set off populace with lower wellness. The contrast between the wellness of preliminary and verifiable populace choose the course task of the improvement.

\section{RESULTS AND DISCUSSIONS}

Table 2: Optimization results for IEEE 33 Bus System

\begin{tabular}{|l|l|l|l|l|}
\hline Cases & $\begin{array}{l}\text { Power losses } \\
\text { KW }\end{array}$ & $\begin{array}{l}\text { DGs } \\
\text { size } \\
(\mathrm{MW})\end{array}$ & $\begin{array}{l}\text { DGs } \\
\text { place } \\
\text { on } \\
\text { buses }\end{array}$ & $\begin{array}{l}\text { DSTATCOM } \\
\text { Placement on } \\
\text { buses }\end{array}$ \\
\hline Base case & 202.7069 & - & - & - \\
\hline $\begin{array}{l}\text { Commercial } \\
\text { loads }\end{array}$ & 23.6583 & $\begin{array}{l}1.23, \\
0.654\end{array}$ & 31,32 & 10 \\
\hline $\begin{array}{l}\text { Constant } \\
\text { loads }\end{array}$ & 26.14 & $\begin{array}{l}1.23, \\
0.654\end{array}$ & 31,32 & 22 \\
\hline $\begin{array}{l}\text { Industrial } \\
\text { loads }\end{array}$ & 20.44 & $\begin{array}{l}1.23, \\
0.654\end{array}$ & 31,32 & 22 \\
\hline Mixed loads & 30.2422 & $\begin{array}{l}1.23, \\
0.654\end{array}$ & 31,32 & 33 \\
\hline $\begin{array}{l}\text { Residential } \\
\text { loads }\end{array}$ & 26.42 & $\begin{array}{l}1.23, \\
0.654\end{array}$ & 31,32 & 26 \\
\hline
\end{tabular}



SIZING WITH HELP OF BACK TRACKING SEARCH ALGORITHM

Table 3: Optimization results of Voltage Profile for 33 Bus Systemof before and after DG and DSTATCOM for different loads

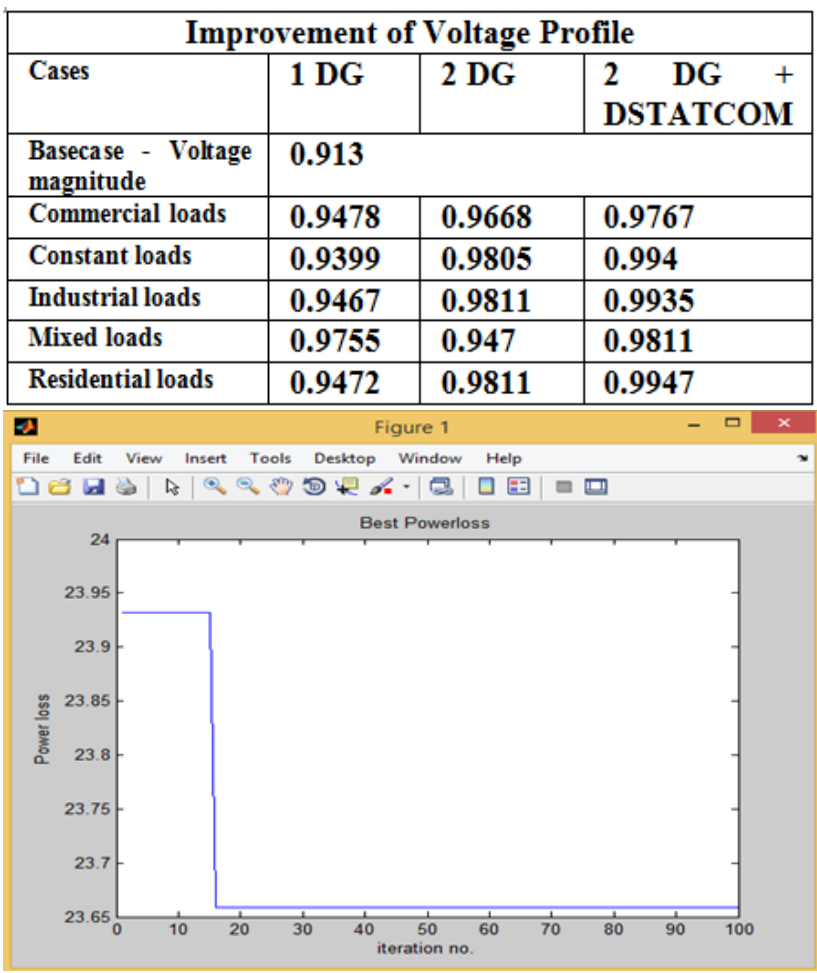

Fig3: Power losses Versus Iteration Number before and after DG \&DSTATCOM placement of IEEE 33 bus system for commercial loads

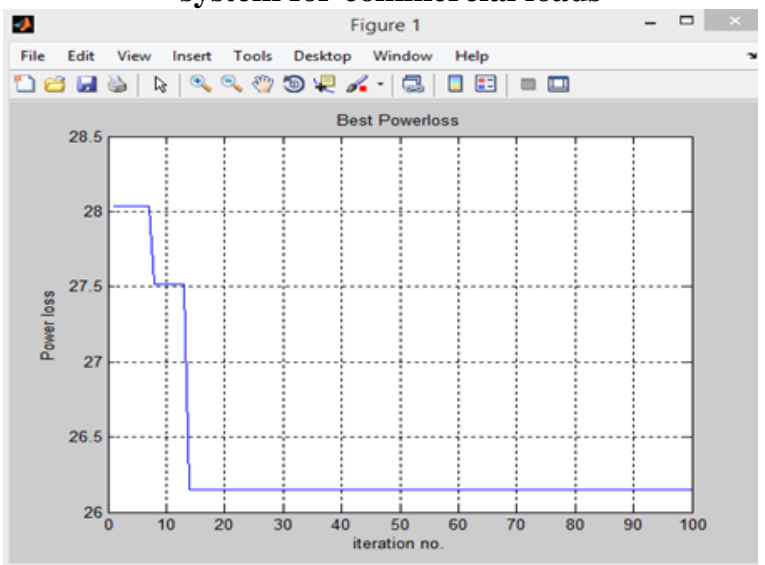

Fig4Power losses Versus Iteration Number of before and after DG \& DSTATCOM placement of IEEE 33 bus system for constant loads

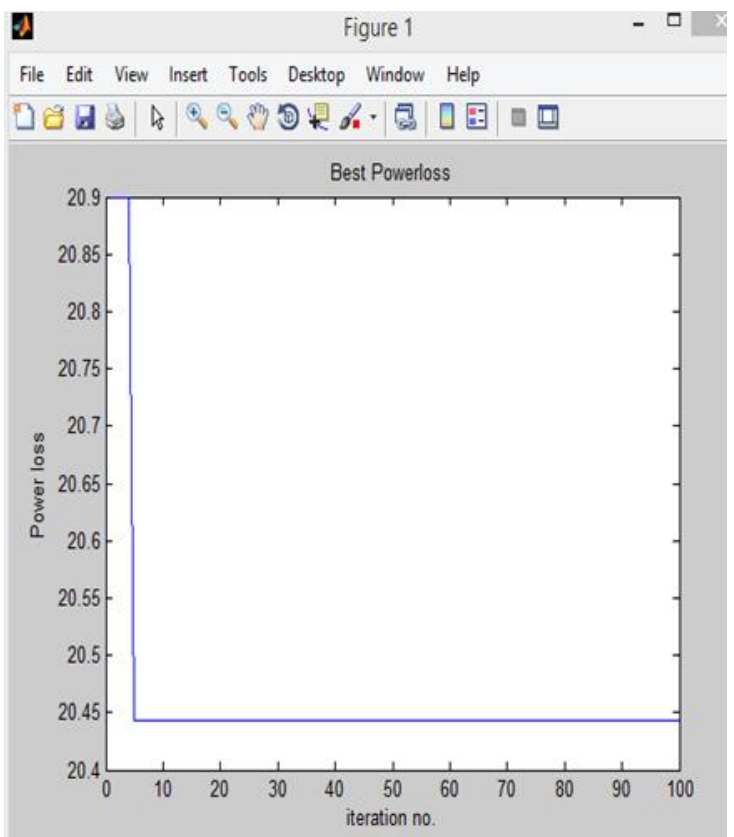

Fig.5Power losses Versus Iteration Number of before and after DG \& DSTATCOM placement of IEEE 33 bus system for Industrial loads

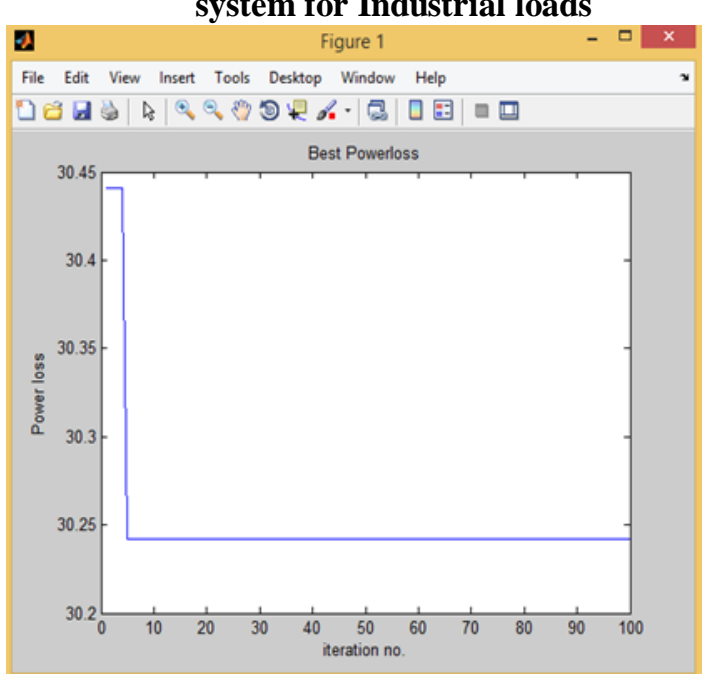

Fig.6Power losses Versus Iteration Number of before and after DG \& DSTATCOM placement of IEEE 33 bus system for mixed loads

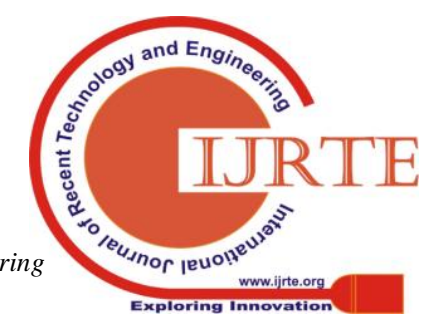




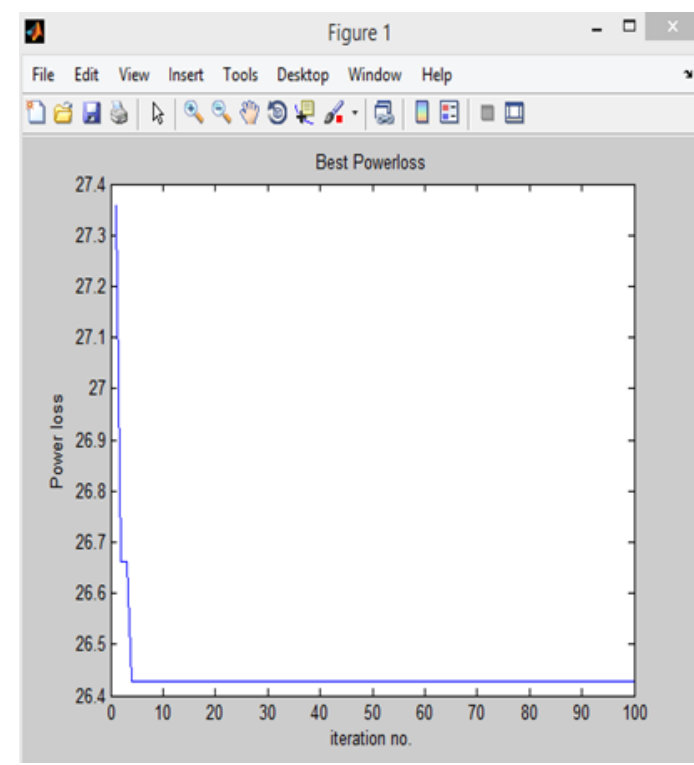

Fig 7Power losses Versus Iteration Number of before and after DG \& DSTATCOM placement of IEEE 33 bus system for residential loads

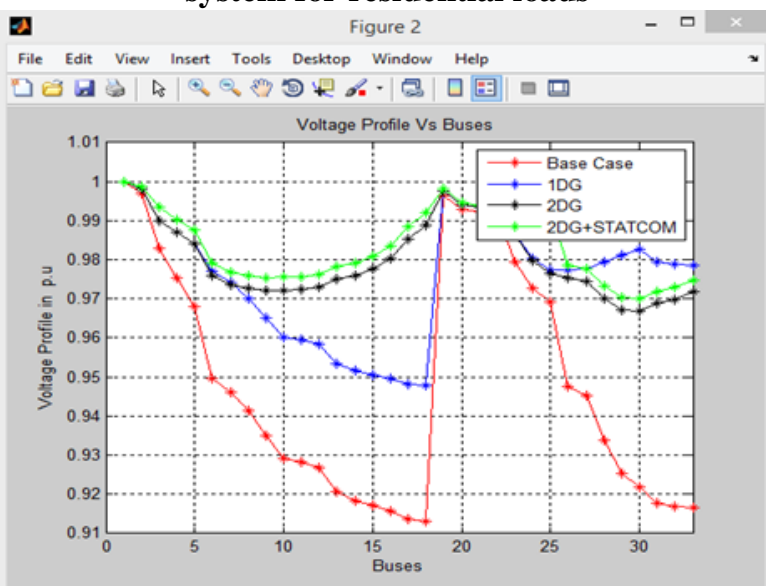

Fig 8: Voltage Profile before and after DG \& DSTATCOM placement for 33 IEEE bus system for commercial loads

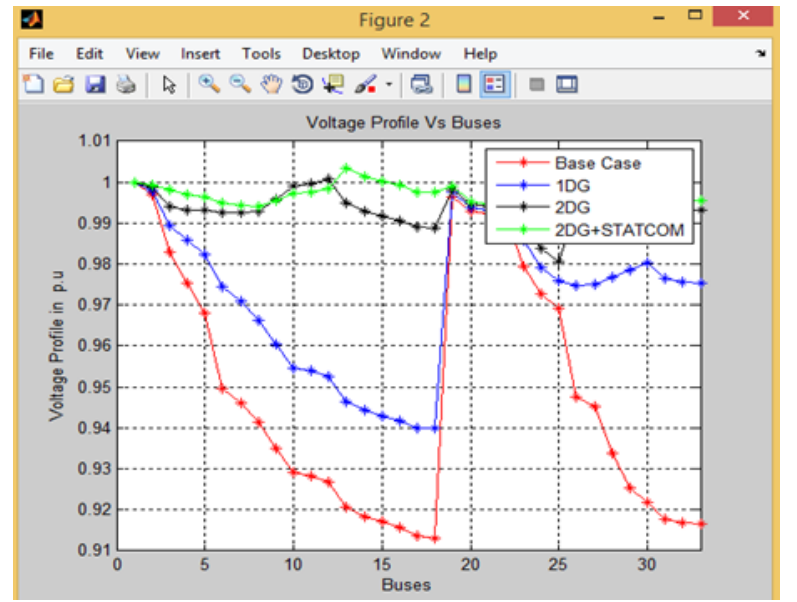

Fig 9: Voltage profile before and after DG \&

DSTATCOM placement for 33 IEEE bus system for different loads

The BSA has been connected to IEEE - 33 transport outspread dissemination system.Optimization has been finished with single and different DGs, with DSTATCOM as appeared previously. Under base case conditions for 33 transport framework the complete genuine power loss of the framework is $202.5635 \mathrm{Kw}$. The base voltage is $0.913 \mathrm{p} . \mathrm{u}$ which happens at transport number 18 . Be that as it may, even with a solitary DG working at 0.85 power factor the genuine power misfortune is decreased to $74.925 \mathrm{Kw}$ and the base framework voltage shoots up to 0.9399 p.u. For 69 transport framework the genuine power misfortune without DG is $224.9032 \mathrm{KW}$, responsive influence misfortune is 102.1234 KVArs and least transport voltage is 0.9096 which happens at transport number 65 . Anyway with a solitary DG working at power factor of 0.85 for consistent burden model the dynamic power misfortune is decreased to $24.0090 \mathrm{KW}$ and the base transport voltage shoots up to 0.9730 p.u.

Figures [2] and [4] demonstrates the voltage profile of IEEE-69 and IEEE-33 transport framework with and without DGs. Figures [3] and [5] demonstrates the voltage profile of various burden model with two DGs. From the plot we can see that the profile is pretty much comparable for two and three DGs. "Henceforth whenever cost is requirement, at that point just two DGs can be liked .According to tables [4], [5], the ideal limit of DG units for burden models contrast from the instance of steady burden". This demonstrates the thought of burden model importantly affects DG limit and area .

\section{CONCLUSION}

In this paper creator proposes another developmental calculation, BSA. Numerical displaying of voltage ward loads i.e., private, mechanical, business, and blended burdens has been introduced. This methodology is definitely not hard to complete and the results persuaded are seen to be incredible, as the perfect territories and size of DGs with DSTATCOM have enhanced the voltage when load changes as can be seen by graphs and the structure setbacks are in like manner reduced and extra cost of movement. The outcomes feature the way that voltage ward burden models affect the power and voltage qualities of a dissemination framework.

\section{REFERENCE}

1. Celli.G, Ghiani.E, M.Loddo, "Voltage profile optimization with Distributed Generation", 2005 IEEE Russia Power Technologies, CD-Ro, ISBN:978-5-93208-0344, Stpeters burg, Russia.

2. EminogluUHocaoglu MH, “A new power flow method, for radial distribution systems including voltage dependent load model" Electro power system Research 2005; 76(1-3); n106-14

3. Zhu; R.P.Broad water; Kwa-Sur Tam; R.Segum; H.Asgeirsson "Impact of DG placement on reliability and efficiency with time varying loads" IEEE Transactions on power systems, Volume 21, Issue :1, Feb 2006, INSPEC Accession Number:8757151.

4. Kejun Qian, Chengke Zhou, M.Allan, Y.Yuan "Effect of load models on assessment of energy losses in distributed generation planning”, IJEPES, 2011.04.003, Vol.33(6):1243-1250, July, 2011.

5. MansourehZangiabadi, Renefeuillet, Hamid Lesani"Assessing the performance and benefits of customers distributed generation developers under uncertainty, Volume 36, Issue 3, 2011, Elsevier Ltd.

6. Duong Quoc Hung, MadarajahMithulanathan, "Multiple Distributed Networks for loss reduction" IEEE Transactions on Industrial Electronics, Volume 60, Issue,
Blue Eyes Intelligence Engineering \& Sciences Publication 
April 2013 INSPEC Accession Number : 13136545.

7. MasoudEsmaili "Placement of minimum distributed generation units observing power losses and voltage stability with network constraints" Published in IET Generation, Transmission \& Distribution, Volume 7 Issue:8, Aug, 2013.

8. M.Kalantari, A.Kazemi, and M.S.Zakerinia "Optimization of Distributed Generation Placement for Minimizing Power Losses and Voltage Profile Improvement Using Genetic Algorithm" Vol 2, no.10, pp.376-381, 2012

9. F.S. Abu-mouti and S.Member, "Optimal Distributed Generation Allocation and Sizing in Distribution Systems via Artificial Bee Colony Algorithm", Vol.26, no.4, pp.2090-2101, 2011.

10. Naruttam Kumar Roy, M.J.Hossain, H.R.Pota"Voltage Profile improvement for distributed wind generation using D-STATCOM", IEEEPublications 24-29July 2011, INSPEC Accession number.12303884

11. Zahersaafin, Fouad Zaro, MutazJawadeh "Voltage Profile improvement using DSTATCOM Based on Artificial Intelligent Techniqua, 2019 IEEE Jordan International Joint Conference Electrical Engg and Information Technology, 8717452

12. Haque $M$ "Load flow solution of distribution systems with voltage dependent load models " Electro power system Res 1996:36(3):151-6

13. Singh.D, Verma.K.S, "Multiobjective Optimization for DG planning with load models" IEEE transaction on power systems, vol.24(1), pp.427-36, 2009. 